\title{
Relative Effectiveness of Conceptual Change Texts with Concept Cartoons and 5E Learning Model with Simulation Activities on Pre-Service Teachers' Conceptual Understanding of Waves
}

\author{
Erdal Taşlıdere* \\ Department of Basic Education, Burdur Mehmet Akif Ersoy University, Burdur, Turkey \\ ORCID: 0000-0002-3158-2483
}

Article history

Received:

23.09.2020

Received in revised form: 11.04.2021

Accepted:

17.04.2021

Key words:

Conceptual understanding;

Concept cartoons;

Conceptual change text;

5 E learning model;

Simulation;

Misconception
The purpose of this study was to investigate both the individual and relative effectiveness of two conceptual change interventions, gender and their interactions on preservice science teachers' conceptual understanding and their misconceptions in mechanical waves. The interventions are conceptual change texts enriched with concept cartoons (CCTCC) and 5E learning model enriched with simulation activities (5ESA) respectively. Participants are 66 sophomores from two intact classes. A quasi-experimental design was used as a research methodology. One group studied the concept of mechanical waves with the CCTCC and the other studied it with the 5ESA. Students' conceptual understanding levels and misconceptions were measured by a Four-Tier Mechanical Waves Misconception Test as pre and post-test. Preliminary analysis indicated that there was no significant difference among the intervention groups' pre-conceptual understanding levels. Individual effects of the treatments from pre to post-tests were investigated by paired-sample t-tests and the main effects of the treatments, gender and their interactions on post-conceptual understanding levels were examined via two-way ANOVA. The results of t-tests showed that both treatments significantly affected learners' conceptual understanding levels individually. ANOVA results yielded a significant treatment effect on behalf of the CCTCC, but the effects of the gender and gender*treatment interaction on students' post-conceptual understanding levels were insignificant. Findings showed that the conceptual change approach accompanied by conceptual change text enriched with concept cartoons is likely to be more effective for increasing students' conceptual understanding level and decreasing their misconceptions in mechanical waves.

\section{Introduction}

In recent years, researchers have focused their attentions on learners' conceptual understanding of mechanical waves at different school levels. Mechanical wave is one of the most important subjects in physics and leads to better understanding of advanced physics concepts such as fluid dynamics, acoustics, optics, quantum mechanics and electromagnetic theory (Kennedy \& de Bruyn, 2011; Tongchai, Sharma, Johnston, Arayathanitkul, \&

\footnotetext{
* Correspondency: etaslidere @ mehmetakif.edu.tr
} 
Soankwan, 2009). Unfortunately, the research reports indicate that most of the students from different educational levels face a range of conceptual difficulties pertaining to mechanical wave and have various misconceptions (Admoko, Yantidewi, \& Oltafia, 2019; Caleon \& Subramaniam, 2010; Goodhew, Robertson, Heron, \& Scherr, 2019; Şengören, Tanel, \& Kavcar, 2009; Kennedy \& de Bruyn, 2011; Maurines, 1992; Menchen \& Thompson, 2003; Tongchai et al., 2009; Tumanggor, Supahar, Kuswanto, \& Ringo, 2020; Wittmann, 2002).

Misconceptions refer to ideas that students have about natural phenomena which are inconsistent with scientific conceptions (Chambers \& Andre, 1997). They are stable cognitive structures that are highly resistant to change and affect learners' understanding of scientific concepts (Nalkiran \& Karamustafaoglu, 2020; Pimpthong, 2015; Treagust \& Duit, 2008). They act as filters and hinder permanent and meaningful learning (Shunk, 2009). To that end, determining learners' misconceptions and remedying them are crucial to promote conceptual understanding (Sendur \& Toprak, 2013). Tumanggor et al. (2020) present that misconceptions on each subtopics of the mechanical waves concept are highly categorized and require specific attentions to remove them. They underline that there is a need for treatments and application of different contemporary methods to eliminate students' lack of conceptual understanding and misconceptions.

It is claimed that traditional instruction is ineffective in improving conceptual understanding (Tongchai et al., 2009). The approaches promoting active participation of students in learning are believed to help learners construct knowledge meaningfully (Kalina \& Powell, 2009) and the learners give meaning to new gained knowledge by associating them with their prior ones (Osborne \& Wittrock, 1983). In the literature, there are alternative teaching approaches and models such as conceptual change approach (Posner, Strike, Hewson, \& Gertzog, 1982), conceptual change texts (Hynd \& Alvermann, 1986; Roth, 1985; Wang \& Andre, 1991; Chambers \& Andre, 1997), concept cartoons (Keogh \& Naylor, 1999; Keogh, Naylor, \& Wilson, 1998), 5E learning model (Bybee, 2009) and Simulations (Azizah, Samsudin, \& Sasmita, 2019) to promote conceptual understanding as alternatives to traditional instruction. They were developed from Piaget's cognitive developmental theory and students gain conceptual understanding based on assimilation, disequilibrium and accommodation (Piaget, 1950; as cited in Wang \& Andre, 1991). Piaget claims that new concept is understood by applying existing mental structures to new one and this process is called as assimilation. If the new concept cannot be understood via existing structures, it produces a state of disequilibrium which motivates the learner to explore the new conception and construct new mental structures. The construction of new mental structure for understanding new concept is called as accommodation.

\section{Conceptual Change Approach}

Conceptual change approach is a model which help learners organize and reconstruct their preliminary knowledge (Posner et al., 1982). It represents an alternative way for encouraging learners to gain conceptual understanding and alter their misconceptions with scientific ones (Thomas \& Kirby, 2020). Posner et al. (1982) suggested an instructional strategy based on conceptual change approach. They proposed four conditions to satisfy conceptual change such as dissatisfaction, intelligibility, plausibility and fruitfulness. According to Posner et al. (1982) the instruction must first induce dissatisfaction about students' preconceptions. Then, a new intelligible concept must be introduced to help students understand it clearly. Third, the new concept must appear plausible; it should be consistent with other forms of knowledge and can solve similar problems presented to the students. 
Finally, the concept must appear fruitful; it should be applied to situations beyond the previous one that led to dissatisfaction.

Researchers think that there are lots of reasons for achieving conceptual change, but they do not agree on the method that is the most effective (Mildenhall \& Williams, 2001). In the literature, there are instructional methods or strategies to achieve conceptual change. For example, use of conceptual change text, concept cartoons, 5E learning model and simulation applications are only some of them. The following sections will inform about them briefly.

\section{Conceptual Change Text}

Conceptual change text is one of the conceptual change instructional strategies. It is a written text that defines common misconception(s) about a natural phenomenon and directly refutes misconception by providing scientifically acceptable ideas by asking learners to make predictions about a given situation (Anam, Widodo, \& Sopandi, 2020; Hynd, 2001; Roth, 1985; Sendur \& Toprak, 2013). The related literature presents that conceptual change text is highly effective for creating conceptual change, promoting meaningful learning and overcoming misconceptions (Aygün \& Tan, 2021; Chambers \& Andre, 1997; Çepni \& Şahin, 2012; Ozkan \& Selcuk, 2015; Sendur \& Toprak, 2013). Testing learners' prior knowledge is the first step in conceptual change text strategy. Then, presentation of the examples and explanations to facilitate learners' understanding is the next step. The written text supports the conceptual change process by indicating the inconsistencies between scientific knowledge and common misconceptions (Kim \& Van Dusen, 1998).

\section{Concept Cartoons}

Concept cartoons propose an innovative teaching and learning strategy through a constructivist view of learning in science (Keogh \& Naylor, 1999). They are instructional tools presenting real-life scientific problem and the characters express their opinions related to the problem (Keogh et al., 1998; Stephenson \& Warwick, 2002). The complex and abstract concepts can be explained easily by the characters in concept cartoons (Stephenson \& Warwick, 2002). They can be developed both as posters and worksheets and be used either as teaching method or instructional material in science courses (Kabapınar, 2009). The related literature presents that use of concept cartoons are quite effective for uncovering learners' ideas (Chin \& Teou, 2009; Keogh et al., 1998; Keogh \& Naylor, 1999), remedying misconceptions (Atasoy \& Ergin, 2017; Keogh \& Naylor, 1999; Kusumaningrum, \& Indriyanti, 2018; Şahin, Durukan, \& Arıkurt, 2017), providing powerful stimulus for students to focus their attention on constructing meaningful explanations and sparking argumentation (İspir \& Aydın, 2020; Keogh \& Naylor, 1999; Stephenson \& Warwick, 2002).

\section{E Learning Cycle Model}

In the late 1980s, the Biological Sciences Curriculum developed a theory-based design for inquiry called BSCS 5Es Teaching model (Bybee, 2009). The BSCS 5Es Instructional model or 5E learning cycle model (5E) has been widely used in science education (Çakir \& Güven, 2019; Şahin et al., 2017) since then. The model provides conceptual change and inquiry learning in classroom environment (Campbell, 2000) by arousing interest and curiosity in learners (van Garderen, Decker, Juergensen, \& Abdelnaby, 2020).

5E includes five different phases: engagement, exploration, explanation, elaboration and evaluation. At the engagement phase, learners' attentions are drawn and their preconceptions 
are revealed. Then, learners are faced with first-hand experiences for the exploration stage. At the explanation phase, the teacher encourages students to explain their understanding from previous experiences. This phase also provides opportunity for teacher to introduce concept and make explanations. In the elaboration phase, learners' understanding is expanded by new experiences. They use their understanding for the new additional activities. Finally, the learners are encouraged to assess their understanding, and teacher evaluates students' progress in achieving the educational objectives at the evaluation stage.

In the last decades, the number of studies searching the effects of the $5 \mathrm{E}$ has increased rapidly. The research generally reports that application of the $5 \mathrm{E}$ leads to greater science achievement, mastery of subject matter, improved reasoning ability and superior process skills than obtained by traditional instructions (Ateş, 2005; Bybee, 2009; Campbell, 2000; Duran, Duran, Haney, \& Scheuermann, 2011; Şahin et al., 2017). A meta-analysis study conducted by Çakir and Güven (2019) showed that the 5E learning model had the strongest effect on academic achievement in physics course, especially at university level. The literature claims that the 5E learning model would be enriched with technology to obtain a good instrument for instructors in teaching previously determined concepts as well as learners to gain $21^{\text {st }}$ century skills (Senan, 2013).

\section{Simulation}

Computer simulation is one of the technological advances and rapidly entered the science classrooms as digital instructional technology (Widiyatmoko, 2018). Simulation is defined as the computerized version of a model that runs over a period to analyze results of predefined interaction (Başer, 2006). Engagements with simulations meet the needs of learner from diverse backgrounds (Martinez, Sweeder, WandenPlas, \& Herrington, 2021). It is highly effective for training learners on a model of reality, when the model is dangerous, difficult and costly (Talan, 2021). It can be used as a complement to or alternative for other forms of instructions to facilitate learners' understanding of scientific concepts (Jimoyiannis \& Komis, 2001), and accepted as an alternative approach to real hands-on laboratory exploration or expository instruction (Ronen \& Eliahu, 2000). Learners can arrange the independent variables and observe the results instantly (Zacharias, 2005). The literature presents successful learning outcomes of simulation activities (Başer, 2006; Bayrak, 2008; Jaakkola \& Nurmi, 2008; Kibirige \& Tsamago, 2019; Martinez et al., 2021; Mckagan, Handley, Perkins, \& Wieman, 2009; Ronen \& Eliahu, 2000; Taşlidere, 2015; Zacharias, 2005). Talan (2021) conducted a meta-analysis study about the effect of simulation technique on academic achievement. The results showed that the simulation technique has a brought impact on students' achievement. The researcher also report that the impact of the technique does not depend on the teaching levels, subject area or application time. It is suggested that the simulations would be used in physics education (Azizah et al., 2019; Jaakkola \& Nurmi, 2008).

In the literature, it is discussed that gender is one of the critical factors that affects students' achievement in science education. Some studies found it as the significant predictor (Mcpanang, 2016; Taslidere, 2020) and the others (Awodun, Oni, \& Aladejana, 2014; Yerdelen-Damar \& Peşman, 2013) found it as insignificant predictor for the science achievement. Likewise, some of the previous studies (Ates, 2005; Chambers \& Andre, 1997; Kibirige \& Tsamago, 2019) reported insignificant, and the others (Chu, Treagust, \& Chandrasegaran, 2009; Wang \& Andre, 1991) found significant interactions between gender and treatments. Hence, as Ates (2005) claims there is no consensus among the study reports 
about the effectiveness of gender and gender*treatment interaction on students' academic performances in science education.

\section{The Related Conceptual Change Studies}

There exist various conceptual change approach studies concerning the individual effects of abovementioned conceptual change text, concept cartoons, the 5E and simulations on students' learning outcomes. The study reports generally presents positive effects of them. But the latest research claim that it is difficult to increase students' conceptual understanding levels and remove their misconceptions completely by using only one conceptual change strategy and hence they suggest combining different conceptual change strategies complementarily (Çepni \& Şahin, 2012; Wilder \& Shuttleworth, 2005). But the extensive literature review indicated that there is limited research integrating different conceptual change strategies. The following ones are only some of them.

Çil (2014) compared the effect of conceptual change approach through the use of conceptual change text and concept cartoons to that of explicit reflective inquiry oriented and implicit instructional approaches in the teaching of Nature of Science. Researcher reported that the use of conceptual change text with concept cartoons is the best way for remedying $7^{\text {th }}$ grade students' misconceptions in the context of nature of science. Likewise, Çil and Çepni (2016) investigated the influence of explicit reflective conceptual change approach, accompanied by conceptual change text and concept cartoons, and explicit reflective inquiry-oriented approach on $7^{\text {th }}$ grade students' understanding of nature of science. They reported that reflective conceptual change approach is more effective in improving students' nature of science conception. Yildirım (2017) searched the effect of conceptual change text enriched with concept cartoons on primary school teacher candidates' conceptual understanding in simple electric circuits. The results revealed that teaching via conceptual change text enriched with concept cartoons was more effective than traditional instruction in increasing learners' conceptual understanding. Atasoy and Ergin (2017) investigated the effect of concept cartoon embedded worksheets on $9^{\text {th }}$ grade learners' conceptual understanding concerning Newton's Laws of Motion. Their results revealed that concept cartoon embedded worksheets not only enhanced students' conceptual understanding but also replaced their misconceptions with scientific conceptions. Sinanoğlu (2017) compared the effectiveness of two interventions, web supported concept cartoons with conceptual change texts and concept cartoons with conceptual change texts prepared as worksheets, on $6^{\text {th }}$ grade students' succession concerning the unit of reproduction, growth and development in plants and animals. The results indicated that the web-supported materials increased students' succession more.

Likewise, there are also studies integrating the 5E learning model with simulation activities in the literature. For example, Taşlidere (2015) investigated the effect of the 5E with simulation activities on pre-service science teachers' achievement in the concept of photoelectric effect. The results showed that the developed treatment affected participants' post-achievement and post-open-ended exam scores significantly. Çetin (2016) suggested sample lesson plan using the 5E learning model with simulation activities for teaching the static electricity concept. Sarı, Hassan, Güven and Şen (2017) studied the effects of the 5E with interactive simulations on $11^{\text {th }}$ grade students' academic achievements and attitudes towards scientific concepts. The results showed that the $5 \mathrm{E}$ with simulation caused significantly better acquisition of scientific concepts and greater positive attitudes towards light concept. Bayram (2019) searched the effects of the simulation supported $5 \mathrm{E}$ and traditionally implemented $5 \mathrm{E}$ on $7^{\text {th }}$ grade students' understanding and interest on electricity concepts. The findings revealed that although the 
treatment developed by simulation supported $5 \mathrm{E}$ did not affect learners' understanding significantly, it influenced their attitudes positively compared to the traditionally implemented $5 \mathrm{E}$ instruction.

\section{Purpose of the Study}

The literature revealed that the number of studies integrating different conceptual change strategies are limited as presented and none of them integrated conceptual change text with concept cartoons, or the $5 \mathrm{E}$ with simulation activities to compare both the individual and relative effects of them on sophomore level science teachers' conceptual understanding and remediating their misconceptions in mechanical waves, which indeed is highly abstract and difficult. It is stated that students indicate the lack of conceptual understanding and serious misconceptions even after the treatments (Caleon \& Subramaniam, 2010; Tumanggor et al., 2020). Also, there is a gap in the literature whether gender interacts with the aforementioned integrated conceptual change treatments in teaching mechanical waves. Hence, the current study aimed to: (1) develop two treatments; Conceptual Change Text enriched with Concept Cartoons (CCTCC) and the 5E Enriched with Simulation Activities (5ESA), (2) investigate both their individual and relative effectiveness of treatments, gender and treatment*gender interaction on sophomore level preservice science teachers' conceptual understanding of mechanical waves and (3) analyze the relative effectiveness of the treatments in remedying the misconceptions in mechanical waves. Hence, the research questions are as follows:

(1) What are the individual effects of treatments (CCTCC; 5ESA) in remediating students' misconceptions about mechanical waves?

(2) What are the individual effects of the treatments on students' conceptual understanding of mechanical waves?

(3) What are the relative effects of the treatments, gender and treatment*gender interaction on students' understanding of mechanical waves?

\section{Method}

\section{Design and Procedure of the Study}

A quasi-experimental method with pre-test post-test control group design was used in the research. This method has been used widely in educational studies since it is difficult to assign participants to both experimental and control groups objectively (Gay, Mills, \& Airasian, 2005; Marczyk, DeMatteo \& Festinger, 2005). Effect of the intervention is analyzed using the pre-test and post-test results (Büyüköztürk, 2013). Comparing the groups may indicate the extent to which intervention attained more achievement or conceptual understanding.

The study began with a detailed review of the literature. Teaching materials were developed by the researcher and checked by an experienced instructor teaching General Physics-III, and two research assistants who had a $\mathrm{PhD}$ degree in science education. Based on their feedback, the suggested revisions were conducted. After administering a Four-Tier Mechanical Wave Misconception Test (MWT) to both groups concurrently as pre-test, the instructions started. The first group was instructed with the CCTCC and the other was instructed with the 5ESA. All instructional activities in both groups were conducted by the same instructor having 21 years of teaching experience. At the end of three-week treatment period, the MWT was reapplied to both groups as post-tests concurrently. Finally, the collected data was analyzed 
and research report was prepared.

\section{Participants}

A convenience sample of 66 sophomore level preservice science teachers studying in a government university in Turkey constituted the participants of the study. Since it was not possible to randomly assign the participants to treatments groups; one class with 33 students (29 female and 5 male) was assigned as the first group which was instructed with CCTCC and the other with 33 students (10 female and 23 male) was assigned as the second group which was instructed with the 5ESA randomly. The average age of the participants is 19 .

In the science teacher training program, students study the concept of mechanical waves within the scope of the compulsory General Physics-III course in the first semester of their second year. Students studied the concepts of thermodynamics, geometrical optics just before the main research.

\section{Measuring Tool}

The MWT was used to measure students' conceptual understanding level and determine their misconceptions concerning the properties and propagation of low-amplitude mechanical waves that propagate through an ideal (linear, non-dispersive, flexible and nondissipative) medium within mechanical waves. The test was originally developed by Caleon and Subramaniam (2010) and translated into Turkish by Taşlidere (2016). The MWT consists of 12 questions measuring 19 misconceptions. Each question has four-tiers; the first and third tiers are the answer and reason tiers which measure students' content and explanatory knowledge, respectively. The second and fourth tiers are the confidence tiers which measure the level of confidence of the students concerning the answer and reason tiers, respectively. The confidence tiers are in six-point Likert type format; "1" and " 6 " correspond to "Just Guessing" and "Absolutely confident" respectively (Caleon \& Subramaniam, 2010). The MWT also enables the researcher to specify the strength and the nature of the misconceptions based on the mean of the second and fourth confidence tiers.

In addition to the MWT, one open ended question was prepared and asked to both treatment groups to evaluate the treatments at the end of the study. The question is: "How do you think the CCTCC (also the 5ESA for the second group) contribute to your understanding of the mechanical waves? Please briefly explain the reason with the rationale." The students in the first group evaluated the CCTCC and the others in the second group evaluated the 5ESA.

\section{Teaching Materials}

Various teaching materials such as lesson plans, simulation handbook manuals, concept cartoon worksheets, conceptual change texts, power point presentation files and homework set were developed to satisfy the treatment fidelity in both groups. All materials were checked by an expert instructor in physics education and two research assistant having $\mathrm{PhD}$ in science education.

Two different lesson plans (one for the CCTCC and the other for the 5ESA) were prepared. The lesson plans for the CCTCC were developed by considering concept cartoon worksheets with conceptual change texts. In the current study, the situations were presented with concept cartoon worksheets and the scientific explanations were provided with the conceptual change texts. For this, four concept cartoon worksheets and four conceptual change texts were 
prepared. Both the concept cartoon worksheet and the conceptual change text have the same contents of (1) the speed of the particle within wave, (2) the factors affecting the speed of wave, (3) the relationship between frequency, wavelength and speed in periodical waves and (4) transfer of waves between different mediums. Each concept cartoon worksheet includes at least three cartoon characters; one presents a scientific answer concerning a problem related to mechanical waves, and the others present wrong or misconception-bound responses about it. The concept cartoon worksheets require students first specify which character is telling the truth and write if they have any other opinion than those of the characters, second, explain the reasons as to why the character is right, and finally discuss their ideas with their classmates. The disequilibrium condition of the conceptual change strategy was achieved with the application of these concept cartoon worksheets. It is thought that selecting the character telling the truth giving justifications and discussing ideas with classmates would trigger disequilibrium. A sample concept cartoon worksheet, which aims to reveal students' opinions about how the frequency of waves change when the waves produced on light rope pass to the heavy one, was given in Appendix B. The intelligibility, plausibility and fruitfulness conditions of the conceptual change approach were aimed to be achieved with the applications of the conceptual change texts. Each text represents the same phenomena discussed in the concept cartoon worksheet briefly and then makes scientific explanations explicitly by clarifying why the character(s) in the concept cartoon worksheets are right (or wrong) one by one. Finally, new situations were introduced and students were encouraged to make sense of them based on previously learned information. A sample conceptual change text was given in Appendix $\mathrm{C}$, which explains how the frequency of waves change when the waves move from light rope to heavy rope related to concept cartoon worksheet given in Appendix B.

The lesson plans for the 5ESA were prepared based on the basic tenets of the 5E and simulation applications. The engagement stages were achieved by showing videos, pictures and asking questions concerning mechanical waves. The exploration stages were achieved with simulation activities. For this, seven wave simulation activities were used. They were developed by Colorado University (PhET Simulation, 2006). The literature suggests conducting simulation activities with worksheets to improve the interaction and enhance higher order thinking skills (McKagan et al., 2009). Hence, to help learners in discovering scientific facts and satisfying consistency between the students and the instructor, seven simulation handbook manuals were prepared. They include directions about how to conduct the activity and a series of questions about what student explored at the end of activity. Students performed each activity alone using a separate computer. With these activities, students were expected to explore (1) the characteristics of mechanical waves (2) the effects of [a] tension (force), [b] linear mass density, [c] amplitude, [d] pulse width, wave speed, and finally (3) the relationships between frequency, wavelength and wave speed. A sample simulation handbook manual which aims to help students discover the effect of tension on pulse speed was given in Appendix D.

Two power point presentations, one for the CCTCC and the other for the 5ESA, were prepared to deliver the course content in line with the lesson plans. The presentations consist of explanations, questions and figures. Both presentations include the same contents, but they differ only in delivering them in line with the lesson plans. Especially the explanation stage of the $5 \mathrm{E}$ were conducted via ppt files. The new situations, which were used in the first group to satisfy the fruitfulness condition of conceptual change, were presented at the exploration stage of the 5E in the second group. Finally, a homework set consisting of six open-ended questions with sub-items was prepared for both groups. The students in the CCTCC group answered 
them just after the concepts were studied, but the students in the 5ESA group answered them at the evaluation phases of the $5 \mathrm{E}$ as the occasion arises in due course.

\section{Data Analysis}

The data was analyzed mainly by both descriptive and inferential statistics. In the descriptive statistics, students' total scores were calculated and the means, standard deviations, skewness and kurtosis values were found for each group. Also, the percentages, nature and strength of misconceptions were determined via descriptive statistics. For the inferential statistics, first independent sample $t$-test was used to determine whether groups' pre-conceptual understanding levels (PRET) were significantly different or not. Then, paired sampled $t$-test was conducted to investigate whether the individual effects of the treatments were significant for increasing students' conceptual understanding levels from the PRET to post-conceptual understanding levels (PSTT). Third, the main effects of the treatments, gender and gender*treatment interaction on the PSTT were examined via two-way ANOVA. Also, students' responses obtained from the open ended question were examined to evaluate the treatments with content analysis briefly.

\section{Results}

\section{Descriptive Statistics}

Students' total scores were calculated out of 12 points; a higher score indicates a higher level of conceptual understanding and a lower score indicates a lower level of conceptual understanding in mechanical waves. As presented, the MWT consists of 12 items with four tiers. Total scores were calculated according to the number of correct items. Accuracy and incorrectness of each item determined considering both answer and reason tiers. If both are correct, then the item was accepted as true and scored as " 1 ", otherwise it was scored as "0" as it was scored by previous research (Caleon \& Subramaniam, 2010). Basic descriptive statistics related to the PRET and PSTT considering participants' gender in both groups are given in Table 1 .

Table 1. Basic descriptive statistics related to the MWT

\begin{tabular}{|c|c|c|c|c|c|c|c|c|c|c|c|c|}
\hline & \multicolumn{6}{|c|}{ ССТСС } & \multicolumn{6}{|c|}{ 5ESA } \\
\hline & \multicolumn{3}{|c|}{ PRET } & \multicolumn{3}{|c|}{ PSTT } & \multicolumn{3}{|c|}{ PRET } & \multicolumn{3}{|c|}{ PSTT } \\
\hline & $\mathrm{F}$ & $\mathrm{M}$ & Total & $\mathrm{F}$ & $\mathrm{M}$ & Total & $\mathrm{F}$ & M & Total & $\mathrm{F}$ & M & Total \\
\hline $\mathrm{N}$ & 29 & 4 & 33 & 29 & 4 & 33 & 23 & 10 & 33 & 23 & 10 & 33 \\
\hline Mean & 1.83 & 2.00 & 1.85 & 5.75 & 6.25 & 5.82 & 2.22 & 2.40 & 2.27 & 3.91 & 5.60 & 4.42 \\
\hline St. Dev. & .84 & .81 & .83 & 2.16 & .96 & 2.05 & 1.34 & .96 & 1.23 & 1.83 & 1.17 & 1.82 \\
\hline Skewness & .72 & .00 & .64 & -.28 & -.86 & -.36 & 1.15 & -.11 & .94 & -.49 & .99 & -.58 \\
\hline Kurtosis & -.15 & 1.50 & -.28 & -.11 & -1.29 & .17 & 1.19 & -.62 & .95 & .31 & .75 & .72 \\
\hline
\end{tabular}

As seen from Table 1, the average mean of the students instructed with the CCTCC increased by 3.97 points, but that of the 5ESA increased by 2.15 points from the PRET to PSTT. It seems that students instructed with the CCTCC seem to gain greater conceptual understanding than the others descriptively. When the data was analyzed in terms of gender, the males seem to gain higher achievement in both groups. In the CCTCC group, the males increased their mean by 4.25 points and the females increased it by 3.92 points from the PRET to PSTT. Likewise, in the 5ESA group, male students increased their mean by 3.20 points, but the females increased it only 1.69 points. Skewness and kurtosis values concerning the PSTT in both groups imply that the data is almost normally distributed. To check the distribution of the data in the gender sub-groups, Shapiro-Wilk normality test was conducted. Because Ak 
(2008, p.10; cited in Can, 2014) suggests conducting this test when the number of observed data is smaller than 30 as in the current study. The test results indicated that the data in both groups distributed normally $(p>.05)$ in terms of the gender. The skewness, kurtosis and histogram graphs also supported the normality of the data.

\section{Percentage, Nature and Strength of Misconceptions}

The changes in the percentage, nature and strength of the misconceptions concerning mechanical waves were investigated from the PRET to PSTT in both groups descriptively. In the current research, the identification of misconceptions and the alternatives of the MTW indicating misconceptions were taken from the study of Caleon and Subramaniam (2010, p.326). They were given in Misconception Identification Table in Appendix A. The percentage of students having certain misconception was calculated according to the related options presented in Misconception Identification Table. For instance, Misconception-9 (M9) is measured by item-11(11.1a, 11.3a) in the MWT. If a student chooses the option of "a" in both first and third tiers, then that student was accepted as having the M9. In their study, Caleon and Subramaniam (2010) classified the misconceptions as significant and insignificant ones. They defined significant misconception as the one which was chosen by at least $10 \%$ of the participants. The one chosen by less than $10 \%$ was labelled as insignificant misconception. The strength of the significant misconception was analyzed under two main categories such as Geniue and Spurious misconceptions concerning the average mean of the second and fourth confidence ratings (MCR). Figure 2 indicates identification of the classification of misconceptions.

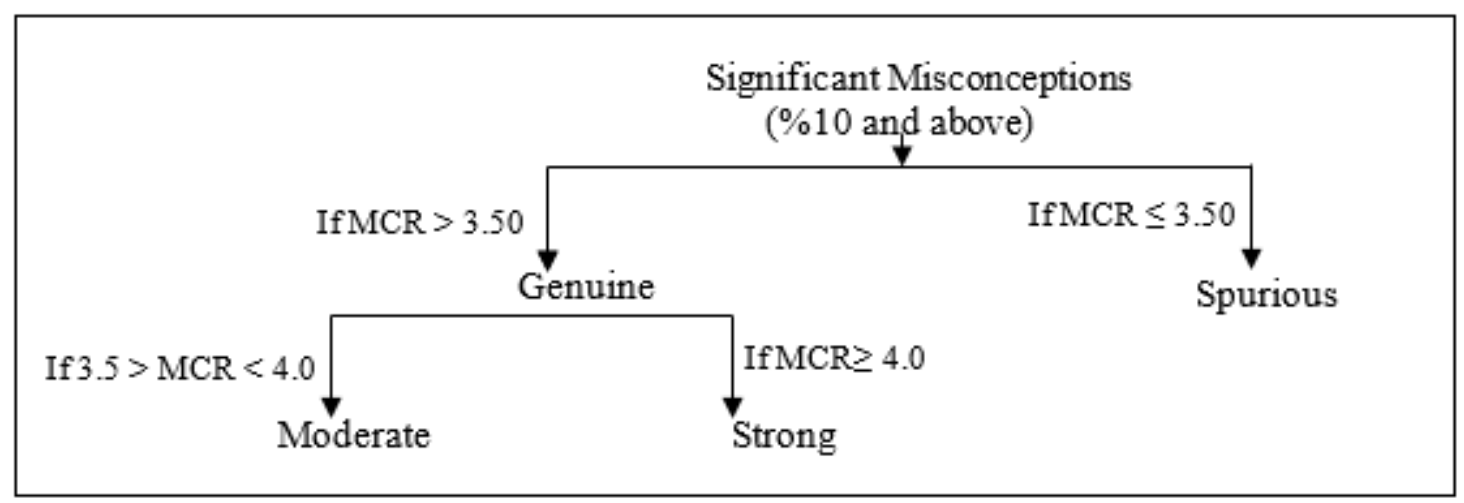

Figure 1. Identification of the classification of misconceptions

As seen from Figure 1, there are two main categories such as Genuie and Spurious misconceptions. A Genuie misconception is a significant one that was expressed with the MCR above 3.5. According to Caleon and Subramaniam (2010), this type of misconception results from lack of understanding of concepts and application of wrong reasoning. The Genuie misconceptions were divided into two sub-classifications such as Moderate and Strong. Moderate and Strong misconceptions are expressed with medium level (between 3.5 and 4.0) and high level (4.0 and above) of the MCR, respectively. A Spurious misconception is the significant one but that was expressed with the low MCR (below 3.50). In their study, Caleon and Subramaniam state that spurious misconception results from lack of knowledge or just guessing. In general, if we give an example, in the CCTCC group, the M9 was considered as significant and moderate misconception; because 17 of the 33 students $(51.5 \%)$ selected both 11.1 (a) and 11.3 (a) for the M9 and the MRC was found as 3.6 out of six points.

The percentage, nature and strength of 19 misconceptions concerning both treatment groups 
from the PRET to PSTT were determined and the results were reported in Table 2. As seen from Table 2, the mean percentages of 19 misconceptions are 40.0 and 37.7 for the CCTCC and 5ESA groups initially. After treatments, they were decreased to 22.3 and 29.1 respectively. In other words, the mean percentage value decreased by 17.7 in the CCTCC group and it decreased by 8.6 in the 5ESA group. The average mean of the MRC for all misconceptions decreased by .5 points (from 3.7 to 3.2) in the CCTCC group, but that of 5ESA increased by .3 points (from 4.1 to 3.8). These indicate that both the average percentage of the students holding misconceptions and their beliefs towards 19 misconceptions decreased more in the CCTCC group in general.

Table 2. Percentage and the MRC value of misconceptions from the PRET to PSTT

\begin{tabular}{|c|c|c|c|c|c|c|c|c|}
\hline \multirow[b]{3}{*}{ Misconceptions } & \multicolumn{4}{|c|}{ ССТCC } & \multicolumn{4}{|l|}{ 5ESA } \\
\hline & \multicolumn{2}{|c|}{ PRET } & \multicolumn{2}{|c|}{ PSTT } & \multicolumn{2}{|l|}{ PRET } & \multicolumn{2}{|c|}{ PSTT } \\
\hline & $\%$ & MCR & $\%$ & MCR & $\%$ & MCR & $\%$ & MCR \\
\hline 1 & 51.5 & 4.6 & 60.6 & 4.9 & 42.4 & 4.7 & 69.7 & 5.4 \\
\hline 2 & 45.5 & 3.1 & 30.0 & 3.5 & 51.5 & 3.8 & 33.3 & 3.6 \\
\hline 3 & 27.3 & 2.8 & 24.2 & 4.1 & 36.4 & 3.7 & 12.1 & 3.8 \\
\hline 4 & 30.3 & 3.3 & 18.2 & 3.7 & 18.2 & 3.5 & 45.5 & 3.9 \\
\hline 5 & 30.3 & 3.8 & 21.2 & 3.1 & 18.2 & 3.2 & 27.3 & 3.8 \\
\hline 6 & 18.2 & 3.7 & 18.2 & 3.6 & 12.1 & 3.5 & 21.2 & 3.6 \\
\hline 7 & 63.6 & 3.6 & 18.2 & 3.8 & 60.6 & 3.6 & 51.5 & 4.8 \\
\hline 8 & 57.6 & 3.5 & 18.2 & 3.7 & 48.5 & 3.5 & 45.5 & 4.6 \\
\hline 9 & 51.5 & 3.6 & 18.2 & 3.8 & 39.4 & 3.7 & 39.4 & 4.7 \\
\hline 10 & 63.6 & 3.8 & 9.1 & 3.7 & 63.6 & 4.1 & 15.2 & 5.2 \\
\hline 11 & 33.3 & 4.3 & 3.0 & 2.0 & 42.4 & 4.9 & 9.1 & 5.7 \\
\hline 12 & 6.1 & 5.0 & 12.1 & 4.2 & 6.1 & 5.0 & 9.1 & 3.8 \\
\hline 13 & 39.4 & 3.2 & 3.0 & 4.0 & 39.4 & 3.2 & 18.2 & 4.5 \\
\hline 14 & 39.4 & 3.3 & 3.0 & 4.0 & 36.4 & 3.5 & 15.2 & 5.0 \\
\hline 15 & 15.2 & 3.6 & 0.0 & 0.0 & 18.2 & 3.6 & 9.1 & 3.7 \\
\hline 16 & 9.1 & 4.0 & 18.2 & 3.8 & 9.1 & 2.7 & 9.1 & 4.3 \\
\hline 17 & 63.6 & 4.0 & 6.1 & 3.5 & 69.7 & 4.3 & 12.1 & 4.5 \\
\hline 18 & 9.1 & 3.3 & 0.0 & 0.0 & 9.1 & 3.5 & 0.0 & 0.0 \\
\hline 19 & 15.2 & 3.8 & 0.0 & 0.0 & 21.2 & 3.5 & 3.0 & 3.5 \\
\hline Average & 40.0 & 3.7 & 22.3 & 3.2 & 37.7 & 3.8 & 29.1 & 4.1 \\
\hline
\end{tabular}

When Table 2 is examined specifically, it is seen that the M17 is the most frequent and strong misconception in both groups (63.6\%, MCR: 4.0 for the CCTCC, and 69.7\%, MCR: 4.3 for the 5ESA) initially. According to the M17, students believe that to make a pulse propagate through a string more quickly, the string must be jerked more quickly and more strongly. After instructions, although the percentage of the M17 in the CCTCC group decreased to 6.1 as an insignificant misconception, that of the 5ESA decreased to 12.1, but it is still a strong misconception from the PRET to PSTT.

As seen from Table 2, the M12 is the least frequent but a strong misconception in both treatment groups (6.1\%, MRC:5.0 in both groups) at the PRET. According to the M12, students believe that the increase in frequency leads to increase in wave speed based on the equation of $V=\lambda * f$. Interestingly, after instructions, the percentage of this misconception increased but the MRC decreased slightly in both groups after instructions (12.1\%, MRC: 4.2 for the CCTCC, and 9.1\%, MRC: 3.8 for the 5ESA). The other significant finding is that the 
percentage of students having the M1 and their beliefs about it increased in both groups after treatments. The percentage values increased by 9.1 and 27.3 in the CCTCC and 5ESA groups respectively, and the misconception is still in strong category. According to the M1, students believe that the wavelength of a wave is the distance between the successive crests of the wave in displacement-time (y-t) graph. Figure 2 shows how the frequency and nature of 19 misconceptions change from the PRET to PSTT in both groups.

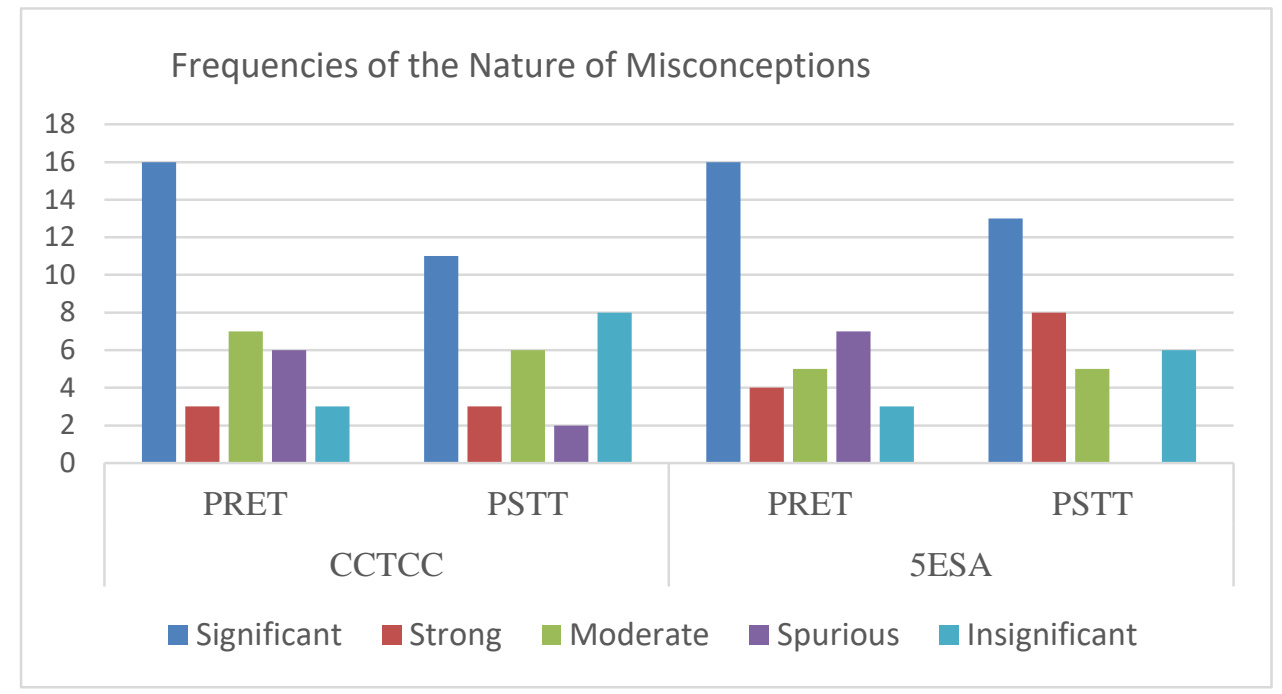

Figure 2. Frequencies and nature of misconceptions in treatment groups from the PRET to PSTT

As Figure 2 presents, there were 16 significant misconceptions in both groups initially. After treatments, the number of significant misconceptions decreased to 11 in the CCTCC group and that of the 5ESA decreased to 13. Although the number of strong misconceptions remained the same in the CCTCC group, that of the 5ESA increased from 4 to 8 . Likewise, the number of moderate misconceptions in the CCTCC group decreased from 7 to 6 , but that of 5ESA remained same. The number of spurious misconceptions in the CCTCC group decreased from 6 to 2, but all spurious ones diminished in the 5ESA group. It is seen that the frequency of insignificant misconceptions in both groups increased as expected; there were 3 initially in both groups, but they increased by 5 and 3 in the CCTCC and 5ESA groups respectively after treatments. In general, Figure 2 presents that although both groups almost had the equal number and nature of misconceptions in mechanical waves, the CCTCC seems to be more effective for decreasing the number and strength of significant misconceptions descriptively.

\section{Inferential Statistics}

Both groups' PRET mean scores were analyzed by the independent sample $t$-test to see whether they differ significantly from each other. Because significant difference in the PRET would affect the PSTT mean scores. The result did not show any statistically significant difference between the PRET mean scores $\left(t_{(56,236)}=1.639, p>.05\right)$.

Individual effects of treatments on students' conceptual understanding level of mechanical waves from the PRET to PSTT were investigated via paired sample $t$-tests. It was hypothesized that each of the CCTCC and 5ESA lead to significant differences between students' conceptual understanding levels of mechanical waves. The assumptions of the test 
(continuous variable, dependent observation, normal distribution, and no outliers) were checked and no problem was encountered. The results are given in Table 3.

Table 3. Paired sample t-test results for each treatment group

\begin{tabular}{lllllllll}
\hline Group & Measure & $\mathrm{N}$ & Mean & Std. Dev. & $d f$ & $t$ & $p$ & $d$ \\
\hline \multirow{2}{*}{ CCTCC } & PRET & 33 & 1.85 & .83 & 32 & -9.98 & .000 & 1.76 \\
& PSTT & 33 & 5.82 & 2.05 & & & & \\
5ESA & PRET & 33 & 2.27 & 1.23 & 32 & -5.59 & .000 & .99 \\
& PSTT & 33 & 4.42 & 1.82 & & & & \\
\hline
\end{tabular}

As seen from Table 3, both the CCTCC and 5ESA led to significant differences from the PRET to PSTT. The students treated with the CCTCC experienced significantly greater the PSTT $(M=5.82, S D=2.05)$ than the PRET $(M=1.85, S D=.83), t_{(32)}=-9.98, p<.05$, $d=1.76$ ). The Cohen's $d$ effect size suggests a highly greater effect size (Green \& Salkind, 2005, p.157). Similarly, the students treated with the 5ESA also experienced significantly greater the PSTT $(M=4.42, S D=1.82)$ than the PRET $(M=2.27, S D=1.23), t_{(32)}=-5.59, p$ $<.05, d=.9$ ). The Cohen's $d$ effect size was found as highly greater too. These results state that both the CCTCC and 5ESA were effective for increasing sophomore level students' conceptual understanding of mechanical waves.

The main effects of treatments, gender and their interactions on PSTT were examined via two-way ANOVA. The probability of rejecting true null hypothesis was set to .05. All assumptions (normality, homogeneity of variances and independency) were checked and no violation was encountered. It was hypothesized that there were no significant effects of treatments, gender and gender*treatment interaction on the population means of the dependent variables of the PSTT. Based on the ANOVA results, the hypothesis was rejected for the independent variable of the treatments $\left(F_{(1,62)}=4.096, p<.05\right)$, but accepted for the gender $\left(F_{(1,62)}=3.121, p>.05\right)$ and gender*treatment interaction $\left(F_{(1,62)}=.940, p>.05\right)$. The results are given in Table 4 .

Table 4. Two-way ANOVA results

\begin{tabular}{lllllll}
\hline Source & $\begin{array}{l}\text { Type III Sum of } \\
\text { Squares }\end{array}$ & df & Mean Square & F & Sig. & $\Pi^{2}$ \\
\hline Corrected Model & 52.744 & 3 & 17.581 & 4.948 & .004 & .193 \\
Intercept & 1082.300 & 1 & 1082.300 & 304.615 & .000 & .831 \\
Treatment & 14.553 & 1 & 14.553 & 4.096 & .047 & .062 \\
Gender & 11.088 & 1 & 11.088 & 3.121 & .082 & .048 \\
Gender*Treatment & 3.340 & 1 & 3.340 & .940 & .336 & .015 \\
Error & 220.286 & 62 & 3.553 & & & \\
Total & 2004.000 & 66 & & & & \\
Corrected Total & 273.030 & 65 & & & & \\
\hline
\end{tabular}

As seen from Table 4, treatment significantly affected the PSTT scores in favor of the CCTCC. The index value of eta-squared $\left(\eta^{2}\right)$ corresponds to the medium effect size (Green \& Salkind, 2005, p.187) which means that $6.2 \%$ of the variance in the PSTT is explained by the treatments. The following pairwise comparison analysis indicated that the CCTCC seem to be significantly effective in increasing students' conceptual understanding level than the 5ESA. The results also showed that gender did not have a significant effect on the PSTT. In other words, other things being equal, males and females gained almost similar conceptual understanding, ignoring whether the participants are in the CCTCC or 5ESA groups. Likewise, the effect of the gender*treatment interaction did not influence the PSTT either. It means that the effect of the treatments on the PSTT did not vary according to the participants' 
gender.

\section{Analyses of the Open-ended Questions}

Finally, students' responses to the open ended question were analyzed briefly by descriptive and content analysis. Expert opinion was gathered about the question, data and coding to ensure content validity. To ensure reliability, expert consent was applied to the consistency of the relationships established between the raw data and the results obtained in line with these data and the comments made. The data was analyzed by two distinct times separately to satisfy the rater reliability. The reliability between the coding was tested by using the formula Reliability = Reconciliation Number $/$ Reconciliation + Non-Settlement Number (Tavşancil \& Aslan, 2001) and found as .94. The opinions of the participants were divided into word, sentence and paragraph analysis units and analyzed (Yıldırım \& Şimşek, 2013). Theme and concepts have been determined. The researcher determined how often the related concepts were repeated and brought the findings together. The findings were supported with the opinions of the students.

The question asked to CCTCT group was as follows; "How do you think the treatment developed by concept cartoon worksheets with conceptual change text contributed to your understanding of the mechanical waves? Please briefly explain the reason with the rationale". The theme and codes revealed in the content analysis for this question are presented in Table 5.

Table 5. The theme and codes of question asked for the CCTCC group

\begin{tabular}{lllc}
\hline Theme & Codes & $\mathbf{n}$ & \% \\
\hline & Positive effect & 30 & 91 \\
& Think, brainstorm and predict & 5 & 15 \\
\multirow{2}{*}{ Effect of the CCTCC } & Express ideas with discussion & 7 & 21 \\
& Everyday events within cartoons and visuality & 9 & 27 \\
& Facilitate permanent learning & 11 & 33
\end{tabular}

As seen from Table 5, most of the students (91\%) present that the application of the CCTCC affected them positively. Quotes from students' expressions are given below.

Student-27: "This method made positive contributions to me; I corrected many things that contradict my way of thinking”.

Student-11: "This method has improved our ability to interpret by providing us with the chance to remember our previous knowledge about the subject and to make predictions by brainstorming in the classroom"

Student-31: "We talked about our ideas and discussed why we think so based on the characters' opinions. Then reading the explanations in the texts helped us realize why we were wrong, and what misconceptions we had".

Student-20: "Cartoons helped us revive events in daily life"

Student-13: "to me, learning by seeing my mistakes was more explanatory and permanent " 
The question asked to the 5ESA group was as follows: "How do you think the treatment developed by $5 \mathrm{E}$ learning model with simulation contributed to your understanding of the mechanical waves? Please briefly explain the reason with the rationale". The theme and codes revealed in the analysis for this question are presented in Table 6.

Table 6. The theme and codes of question asked for the 5ESA group

\begin{tabular}{llll}
\hline Theme & Codes & n & \% \\
\hline \multirow{3}{*}{ Effect of the 5ESA } & Positive effect & 23 & 69 \\
& Simulation of events & 12 & 36 \\
& Attention and curiosity & 8 & 24 \\
& Facilitate permanent learning & 9 & 27 \\
\hline
\end{tabular}

As seen from Table 6, according to $69 \%$ of the students, the application of the 5ESA affected them positively. Quotes from students' expressions are given below.

Student-22: "The method made a positive contribution because we did the activities ourselves"

Student-13: "Using the simulation, seeing the relationship between the concepts of frequency, period, wavelength and wave speed made me understand the subject"

Student-7: "The method attracted my interest in the subject of waves and increased my curiosity"

Student-31: "Visuality made me learn the wave concept meaningfully and permanently"

\section{Discussion and Conclusion}

The current study investigated both the individual and relative effects of two treatments (CCTCC, 5ESA), gender and gender*treatment interactions on sophomore level pre-service science teachers' conceptual understanding decreasing their misconceptions in mechanical waves. The statistical results showed that both treatments affected students' conceptual understanding levels significantly from the PRET to PSTT. On the other hand, the relative effect of the CCTCC was significantly greater than the 5ESA concerning students' post-test scores. The effects of gender and gender*treatment interaction on the PSTT were found to be insignificant.

One of the significant findings of the current research is that both the CCTCC and 5ESA were effective for increasing students' conceptual understanding levels in mechanical waves individually. This finding supports the results of the previous conceptual change research which integrated concept cartoon worksheets with conceptual change texts (Atasoy \& Ergin, 2017; Çil 2014; Çil \& Çepni, 2016; Yıldırım, 2017) and the 5E with simulations (Sarı et al., 2017; Taşlidere, 2015). It seems that the integration of concept cartoon worksheets with conceptual change texts and that of the $5 \mathrm{E}$ with simulation applications completed each other and made significant contributions to students' conceptual understanding of the mechanical waves.

The success of the CCTCC may be attributed to both concept cartoon worksheets and conceptual change text. It is thought that the presentation of scientific phenomena with concept cartoons worksheets satisfied the dissatisfaction condition of the conceptual change 
approach. For this, each student selected his/her favorite character and wrote why the character is right by stating reasoning into the blank under the worksheet. This process activated students' previous knowledge as Student-11 presents. Then, encouragement of students to express and defend their ideas in classroom environment led them support their misconceptions or refute their classmates' opinions. Suggestion of various opinions produced confusion in minds about the accuracy of their responses as Student-31 presents. The intelligibility, plausibility and fruitfulness conditions of the conceptual change approach were accomplished with the implementation of conceptual change text. For this, conceptual change texts were distributed to each student. First each one read the text presenting simple, comprehensible and plausible knowledge that explains why the ideas of each cartoon character is wrong or right step by step. Then the instructor reread the texts loudly by making explanations to convince learners about the accuracy of right characters' opinion. As Student13 states, learning by realizing their mistakes would have made significant contributions to students' conceptual understanding. And finally, the presentation of a new situation related the concept provided learners with the opportunity of applying their newly learned knowledge in understanding the novel situation. Further, the homework set enabled students check and evaluate their understanding. Hence, it is thought that easy application of the concept cartoon worksheets with conceptual change texts paved the way for conceptual understanding of mechanical waves. The concept cartoon worksheets and conceptual change texts were in harmony as in the study of Atasoy and Ergin (2017).

The success of the 5ESA may also be attributed to the successful application of the 5E with simulation activities. As Taşlidere (2015) reported, both the 5E and simulation complemented each other and five phases of the $5 \mathrm{E}$ were accomplished effectively. It is thought that the presentation of interesting videos (such as dancing of crops in a crop field with the wind, the Mexican wave in a stadium and alike) drew students' attention towards the wave concept for the engagement stages. The conduction of simulation activities step by step via resorting to simulation handbook manuals led students discover the scientific facts as Student-13 states. The use of simulations provided visuality and helped students realize the concepts as reported by Student-31. The open ended questions asked at the end of each step of the activity kept students' interest alive. The response of Student-7 supports this claim. In the explanation phase, the questions asked by the instructor based on previously discovered experiences and the encouragements to respond and explain the reasons of experiences made learners mentally active. Additionally, the instructor's scientific and comprehensible explanations satisfied students. Upon explanations, the presentations of new situations (the same ones as in the CCTCC group) gave the students the opportunity to use their learning in explaining the new situations. And finally, assignments of the homework set (which is also the same as is in the CCTCC group) led students to evaluate their understanding of mechanical wave concept. The successful application of the 5ESA supported Çepni and Şahin (2012), who suggested using different teaching methods within the $5 \mathrm{E}$. The integration of the SA with the $5 \mathrm{E}$ was simple, straightforward and easily applicable in teaching mechanical waves.

The most significant finding of the current research is that although each of the CCTCC and 5ESA were effective individually, a statistically significant difference was found between treatments on behalf of the CCTCC in increasing students' conceptual understanding of mechanical waves. The result revealed that, although the pre-conceptual understanding levels of the students in both groups were almost similar, the students instructed with the concept cartoon worksheets with the conceptual change text increased their conceptual understanding significantly compared to the others. Since the current study is the first one investigating the relative effectiveness of the CCTCC and 5ESA in physics, the obtained finding is 
outstanding. As presented, the percentage of the students reporting the positive effect of treatment is greater in the CCTCC (91\%) than that of the students in the 5ESA group (69\%). It is thought that the use of concept cartoon worksheet with conceptual change text might have alerted students more in activating previous knowledge and produced dissatisfaction which triggered students' eagerness to learn more. The presentation of mechanical wave problems with concept cartoon worksheets via characters would have helped students concretize the concepts more. And supplementation of intelligible, plausible information and new situations might have satisfied students, and encourage learners use their knowledge with conceptual change texts. The content analysis results supported the above claim; $27 \%$ of the students stated that the discussions based on characters' ideas and explanations of text helped them realize why they were wrong and what misconceptions they had. These might have led to better scientific understanding of the CCTCC group students than the others in mechanical waves.

The current study showed that effectiveness of the CCTCC and 5ESA did not vary with gender. In other words, the conceptual change features accompanied by the CCTCC and 5ESA seemed to work effectively for both males and females. This result supports the finding of the previous research (Ates, 2005; Chambers \& Andre, 1997; Kibirige \& Tsamago, 2019; Taşlidere, 2013), but contradicts with those of the others (Chu et al., 2009; Wang \& Andre, 1991). Ates (2005) found that the learning cycle method was equally effective in teaching direct current concept for female and male when participants' pre-knowledge level was controlled. Chambers and Andre (1997) concluded that both female and male students gained an almost similar conceptual understanding of electricity from the application of conceptual change text when they included students' experience, interest and pre-knowledge levels into the analysis. Kibirige and Tsamago (2019) reported that use of simulations did not produce significant difference among the female and male students' understanding of wave concept. Similarly, Taşlidere (2013) stated that the use of the concept cartoon worksheet was equally effective in teaching geometrical optics for both males and females when learners' prior knowledge level was controlled. In their study, Wang and Andre (1991) claim that the instructional manipulations may have different effects for the females and males because of differential motivation. But in this research, the instructor did not observe any differential motivation between males and females; both actively participated in the study, took part in discussions and activities in all groups. This may have led to the insignificant effect of gender and gender*treatment interaction as in the study of Taşlidere (2013). Even, there is no theoretical explanation for this outcome for the topic of mechanical waves concept. Hence, this may be searched deeply in further studies.

In concern with students' conceptual understanding, although both the CCTCC and 5ESA were effective in decreasing students' misconceptions in mechanical waves, the CCTCC seems to be more efficient than the 5ESA. Although the number of significant misconceptions were almost equal in both groups initially, the CCTCC seemed to be more effective in decreasing the number of significant misconceptions than the 5ESA did. In other words, the number of insignificant misconception increased from three to eight in the CCTCC, but that of the 5ESA increased from three to six from the PRET to PSTT. However, neither the CCTCC nor the 5ESA removed students' misconceptions entirely. This significant finding supported those of the previous research (Atasoy \& Ergin, 2017; Bezen \& Bayrak, 2020; Çepni \& Şahin, 2012; Duit \& Treagust, 2003; Taşlıdere, 2013; 2015) which claim that conceptual change cannot remediate the misconceptions entirely. As Çepni and Şahin (2012) report, all students learn and understand in different ways, and hence it may be even difficult to remove all misconception completely by combining different conceptual change strategies. 
Yet it is still believed that combining different conceptual change strategies would be more useful than using just one of them as has been underpinned in previous studies (Çepni \& Şahin, 2012; Şahin et al., 2017).

The results also revealed significant findings concerning the misconceptions in mechanical waves concept. It was detected that the M17 was the most frequent and strong misconception in both groups initially (63.6\% in the CCTCC, $69.6 \%$ in the 5ESA). Students used to believe that to make a pulse propagate through a string more quickly, the string must be jerked more strongly and quickly. This misconception was also detected in the previous studies (Caleon \& Subramaniam, 2010; Goodhew et al., 2019; Kennedy \& De Bruyn, 2011; Maurines, 1992; Taşlidere, 2016; Tongchai et al., 2009). According to the researchers (Maurines, 1992; Şengören et al., 2009; Wittmann, 2002), the M17 results from students' tendency to explain the motion of the pulse in a medium with mechanically based approach; learners tend to consider the pulse as an object and the wave source as the mechanism that moves that object. The findings showed that after instructions, the M17 decreased to $6.1 \%$ in the CCTCC and to $12.1 \%$ in the 5ESA at the PSTT. It seems that the M17 is still a strong and significant misconception for the students treated in the 5ESA group. Another frequent but moderate misconception was the M7 in both groups previously. According to this one, students $(63.6 \%$ in the CCTCC, $60.6 \%$ in the 5ESA) used to believe that when waves propagate from a medium with lower mass density to a medium of greater mass density, their frequency decreases. Similar findings were also reported in the previous research (Caleon \& Subramaniam, 2010; Taşlıdere, 2016). It was reported that the M7 results from students' tendency of relating the frequency of wave to the characteristics of the medium (Barman, Barman, \& Miller, 1996; Menchen \& Thompson, 2003). Learners believe that heavy rope resists the wave more and fewer waves will advance in the same time period on the heavy rope (Caleon \& Subramaniam 2010; Goodhew et al., 2019). The finding showed that, the M7 decreased to $18.2 \%$ (as moderate) in the CCTCC and to $51.5 \%$ (as still strong) in the 5ESA groups, respectively. Another significant finding is that the M1 was the frequent and strong (51.5\% in the CCTCC, $42.4 \%$ in the 5ESA) initially. Students used to believe that the wavelength of a wave is the distance between the successive crests of the wave in a displacement-time (y-t) graph. This misconception was also found in the previous research (Caleon \& Subramaniam, 2010; Taşlidere, 2016; Tumanggor et al., 2020). Interestingly, even after treatments, the M1 increased to $60.6 \%$ and $69.7 \%$ as in strong category in the CCTCC and 5ESA respectively. According to Tumanggor et al. (2020), most of the students tend to assume all wave charts have the same variable on each axis and see the wave graph as a representative wave propagation through the medium. Similarly, $57.1 \%$ of the physics teacher candidates in their study indicated the M1 (as in high category) after they had studied the mechanical wave concept. Hence, special attention should be given to this misconception while implementing the treatments in the following studies.

In conclusion, the use of both the concept cartoons worksheet with conceptual change texts and $5 \mathrm{E}$ with simulations may have a particular value for preservice science teacher education. Especially, conceptual change oriented teaching conducted via concept cartoon worksheets with conceptual change texts may promote future science teachers' conceptual understanding, remediate their misconceptions and hence affect most of the future science learners. This research may provide both the researchers and future science teachers with opportunities of defining the development and implementation of concept cartoon worksheets with conceptual change text together. 


\section{Limitation and Suggestions}

This study was conducted with 66 sophomore level pre-service science teachers studying in a government university in the unit of mechanical waves. Further studies could also compare the relative effects of the CCTCC and 5ESA on students' conceptual understanding and on decreasing misconceptions of mechanical waves by increasing the sample size using similar study groups in other state universities. Their results could be compared with those of the current one.

Findings indicated that pre-service science teachers had significant and strong misconceptions in the contexts of mechanical waves. They have conceptual understanding difficulties about the graphical representation of waves, speed of waves, and relationships between the frequency of wave, wave source and medium property. Especially, the instructors should pay attention to the M17, M7 and M1. They should come up with scientifically well-developed treatments using concept cartoon worksheets with conceptual change texts considering the aforementioned misconceptions.

\section{References}

Admoko, S., Yantidewi, M., \& Oktafia, R. (2019, December). The implementation of guided discovery learning using virtual lab simulation to reduce students' misconception on mechanical wave. Paper presented at the Mathematics, Informatics, Science and Education International Conference (MISEIC), Indonesia. Full text retrieved from https://iopscience.iop.org/article/10.1088/1742-6596/1417/1/012089/pdf

Anam, R. S., Widodo, A., \& Sopandi, W. (2020). Conceptual change texts to improve teachers' misconception at verbal and visual representation on heat conduction concept. Jurnal Pendidikan Fisika Indonesia, 16(2), 63-71. doi: 10.15294/jpfi.v16i2.20742

Atasoy, Ş., \& Ergin, S. (2017). The effect of concept cartoon-embedded worksheets on grade 9 students' conceptual understanding of Newton's laws of motion. Research in Science \& Technological Education, 35(1), 58-73 doi: 10.1080/02635143.2016.1248926

Ates, S. (2005). The effectiveness of the learning-cycle method on teaching DC circuits to prospective female and male science teachers. Research in Science and Technological Education, 23(2), 213-227. doi:10.1080/02635140500266518

Awodun, A. O., Oni, S. A., \& Aladejana, A. L. (2014). Students' variables as predictor of secondary school students' performance in physics. International Journal of Scientific and Research, 4, 541-545.

Aygün, M., \& Tan, M. (2021). The impact of mass on action-reaction forces during a collision: using a conceptual change text or traditional expository text to overcome misconception. Pamukkale University Journal of Education, (51), 65-91. doi: 10.9779.pauefd.690966

Azizah, N., Samsudin, A., \& Sasmita, D. (2019). Development of computer simulationassisted conceptual change model (CS-CCM) to change students' conception on gas kinetic theory. J. of Phys.: Conf. Ser., 1280(5), p. 052036. Full text retrieved from https://iopscience.iop.org/article/10.1088/1742-6596/1280/5/052036/pdf

Barman, C. R., Barman, N. S., \& Miller, J. A. (1996). Two teaching methods and students' understanding of sound. School Science and Mathematics, 96(2), 63-67.

Başer, M. (2006). Effects of conceptual change and traditional confirmatory simulations on pre-service teachers' understanding of direct current circuits. Journal of Science Education and Technology, 15(5), 367-381. doi:10.1007/s10956-006-9025-3 
Bayrak, C. (2008). Effects of computer simulations programs on university students' achievements in physics. Turkish Online Journal of Distance Education, 9(4), 53-62.

Bayram, Y. (2019). The effect of simulations supported 5e learning cycle model on seventh grade students' understanding and interest on electric concepts. (Unpublished master's thesis). Bartın University, Bartın.

Bezen, S., \& Bayrak, C. (2020). Teaching mechanical waves by inquiry-based learning. Journal of Baltic Science Education, 19(6), 875-892.

Büyüköztürk, S. (2013). Data analysis handbook for social sciences. Ankara: Pegem Academy Publishing.

Bybee, R. W. (2009). The BSCS 5E instructional model and 21st century skills a commissioned paper prepared for a workshop on exploring the intersection of science education and the development of $21^{\text {st }}$ century skills. Retrieved from https://citeseerx.ist.psu.edu/viewdoc/download?doi=10.1.1.674.6559\&rep=rep1\&type $=$ pdf

Çakir, N. K., \& Güven, G. (2019). Effect of 5E learning model on academic achievement and attitude towards the science course: A meta-analysis study. Çukurova University Faculty of Education Journal, 48(2), 1111-1140.

Caleon, I., \& Subramaniam, R. (2010). Do students know what they know and what they don't know? Using a four-tier diagnostic test to assess the nature of students' alternative conceptions. Research in Science Education, 40, 313-337, doi:10.1007/s11165-0009-9122-4

Campbell, M. A. (2000). The effects of the 5E learning cycle model on students' understanding of force and motion concept (Unpublished master's thesis). Millersville University, Pennsylvania.

Can, A. (2014). Quantitative data analysis in the scientific research process with SPSS. Ankara. Pegem Akademi Publishing.

Çepni, S., \& Şahin, Ç. (2012). Effect of different teaching methods and techniques embedded in the $5 \mathrm{E}$ instructional model on students' learning about buoyancy force. International Journal of Physics \& Chemistry Education, 4(2), 97-127.

Çetin, A. (2016). Designing a lesson with 5e learning cycle and simulations for static electricity subject in physics. Academia Journal of Educational Research, 1(1), 36-41.

Chambers, S.K., \& Andre, T. (1997) Gender, prior knowledge, interest, and experience in electricity and conceptual change text manipulations in learning about direct current. Journal of Research in Science Teaching, 34, 107-123.

Chin, C., \& Teou, L. Y. (2009). Using concept cartoons in formative assessment: Scaffolding students' argumentation. International Journal of Science Education, 31(10), 13071332. doi: 10.1080/09500690801953179

Chu, H.-E, Treagust, D. F., \& Chandrasegaran, A. L. (2009). A stratified study of students' understanding of basic optics concepts in different contexts using two-tier multiple choice items. Research in Science \& Technological Education, 27(3), 253-265. doi: $10.1080 / 02635140903162553$

Çil, E. (2014). Teaching nature of science through conceptual change approach: conceptual change texts and concept cartoons. Journal of Baltic Science Education, 13(3), 339350.

Çil, E., \& Çepni, S. (2016). The effectiveness of conceptual change texts and concept clipboards in learning the nature of science. Research in Science \& Technological Education, 34(1), 43-68. doi: 10.1080/02635143.2015.1066323

Duit, R., \& Treagust, D. F. (2003). Conceptual change: A powerful framework for improving science teaching and learning. International journal of science education, 25(6), 671688. doi: 10.1080/09500690305016 
Duran, E., Duran, L., Haney, J., \& Scheuermann, A. (2011). A learning cycle for all students. The Science Teacher, 78(3), 56-60.

Gay, L. R., Mills, G. E. \& Airasian, P. (2005). Educational research: Competencies for analysis and application (8rd ed.). Upper Saddle River, NJ: Pearson Education.

Goodhew, L. M., Robertson, A. D., Heron, P. R., \& Scherr, R. E. (2019). Student conceptual resources for understanding mechanical wave propagation. Physical Review Physics Education Research, 15(2), 020127. doi: 10.1103/PhysRevPhysEducRes.15.020127

Green, S., \& Salkind, N. (2005). Using SPSS for windows and macintosh: Analyzing and understanding data (4th edition), New Jersey: Prentice-Hall.

Hynd, C. (2001). Persuasion and its role in meeting educational goals. Theory into Practice, 40(4), 270-277.

Hynd, C., \& Alvermann, D. E (1986). The role of refutational text in overcoming difficulty with science concepts. Journal of Reading, 29, 440-446.

İspir, E., \& Aydın, M. (2020). The effect of the concept cartoons used in the teaching of simple machines unit on the achievement and conceptual comprehension levels of 8th grade students Dicle University Journal of Ziya Gökalp Faculty of Education, 1(38), 58-71. doi: http://dx.doi.org/ 10.14582/DUZGEF.2021.154

Jaakkola, T., \& Nurmi, S. (2008). Fostering elementary school students' understanding of simple electricity by combining simulation and laboratory activities. Journal of Computer Assisted Learning, 24, 271-283. doi:10.1111/j.1365-2729.2007.00259.x

Jimoyiannis, A., \& Komis, V. (2001). Computer simulations in physics teaching and learning: A case study on students ${ }^{\text {ee }}$ understanding of trajectory motion. Computers and Education, 36(2), 183-204.

Kabapınar, F. (2009). What makes concept cartoons more effective? Using research to inform practice. Education and Science, 34(154), 104-118.

Kalina, C., \& Powell, K. C. (2009). Cognitive and social constructivism: Developing tools for an effective classroom. Education, 130(2), 241-250.

Kennedy, E. M., \& de Bruyn, J. R. (2011). Understanding of mechanical waves among second-year physics majors. Canadian Journal of Physics, 89(11), 1155-1161.

Keogh, B., \& Naylor, S. (1999). Concept cartoons, teaching and learning in science: An evaluation. International Journal of Science Education, 21(4), 431-446.

Keogh, B., Naylor, S., \& Wilson, C. (1998). Concept cartoons: A new perspective on physics education. Physics Education, 33(4), 219-24.

Kibirige, I., \& Tsamago, H. E. (2019). Grade 10 learners' science conceptual development using computer simulations. EURASIA Journal of Mathematics, Science and Technology Education, 15(7), 1-17.

Kim, S. I., \& Van Dusen, L. M. (1998). The role of prior knowledge and elaboration in text comprehension and. The American Journal of Psychology, 111(3), 353-378.

Kusumaningrum, I. A., \& Indriyanti, N. Y. (2018, May). Concept cartoons for diagnosing student's misconceptions in the topic of buffers. Paper presented at the $1 \mathrm{st}$ International Conference on Science, Mathematics, Environment and Education, Indonesia. Full text retrieved from https://iopscience.iop.org/article/10.1088/17426596/1022/1/012036/pdf

Marczyk, G., DeMatteo, D., \& Festinger, D. (2005). Essentials of research design and methodology. Canada: John wiley \& sons, Inc.

Martinez, B. L., Sweeder, R. D., VandenPlas, J. R., \& Herrington, D. G. (2021). Improving conceptual understanding of gas behaviour through the use of screencasts and simulations. International Journal of STEM Education, 8(1), 1-13.

Maurines, L. (1992). Spontaneous reasoning on the propagation of visible mechanical signals. International Journal of Science Education, 14(3), 279-293. 
McKagan, S. B., Handley, W., Perkins, K. K., \& Wieman, C. E. (2009). A Research-based curriculum for teaching the photoelectric effect. American Journal of Physics, 77(1), 87-95. doi: 10.1119/1.2978181

Menchen, K. V., \& Thompson, J. R. (2004, September). Pre-service teacher understanding of propagation and resonance in sound phenomena. In AIP Conference Proceedings (Vol. 720, No. 1, pp. 65-68). American Institute of Physics.

Mildenhall, P. T., \& Williams, J. S. (2001). Instability in students' use of intuitive and Newtonian models to predict motion: the critical effect of the parameters involved. International Journal of Science Education,23(6), 643-660. doi: 10.1080/09500690117839

Mkpanang, J. T. (2016). Effects of classwide and reciprocal peer tutoring strategies on students' mathematical problem-solving achievement in electricity concepts in physics. International Journal of Education, Learning and Development, 4(3), 37-44

Nalkiran, T., \& Karamustafaoğlu, S. (2020). Prediction-observation-explanation (poe) method and its efficiency in teaching "work, energy, power" concepts. International Journal of Assessment Tools in Education, 7(3), 497-521.

Osborne, R. J., \& Wittrock, M. C. (1983). Learning science: A generative process. Science education, 67(4), 489-508.

Ozkan, G., \& Selcuk, G. S. (2015). Effect of Technology Enhanced Conceptual Change Texts on Students' Understanding of Buoyant Force. Universal Journal of Educational Research, 3(12), 981-988. doi: 10.13189/ujer.2015.031205

PheT Simulation (2006). Photoelectric Effect (1.10) [Physics Education Technology Project]. Retrieved from https://phet.colorado.edu/en/simulations/filter?subjects=sound-andwaves \&sort=alpha\&view $=$ grid

Pimthong, P. (2015). A study of the effect of affective and social factors on teaching for conceptual change in primary science. Science education international, 26(3), 376391.

Posner, G., J., Srike, K. A., Hewson, P. W., \& Gertzog, W. A. (1982). Accommodation of a scientific conception: Toward a theory of conceptual change. Science Education, 66, 211-227. doi:/10.1002/sce.3730660207

Ronen, M., \& Eliahu, M. (2000). Simulation - a bridge between theory and reality: the case of electric circuits. Journal of Computer Assisted Learning, 16(1), 14-26. doi:10.1046/j.1365-2729.2000.00112x

Roth, K. J. (1985, April). Conceptual Change Learning and student processing of science texts. Paper presented at the annual meeting of American Research Association, Chicago, Illinois. Full text retrieved from https://files.eric.ed.gov/fulltext/ED267980.pdf

Şahin, Ç., Durukan, Ü. G., \& Arıkurt, E. (2017). Effect of 5e teaching model on primary school pre-service teachers' learning on some astronomy concepts. Journal of Baltic Science Education, 16(2), 148-162

Sarı, U., Hassan, A. H., Güven, K., \& Şen, Ö. F. (2017). Effects of the 5E teaching model using interactive simulation on achievement and attitude in physics education. International Journal of Innovation in Science and Mathematics Education (formerly CAL-laborate International), 25(3), 20-35.

Senan, D.C. (2013). Infusing BSCS 5E instructional model with multimedia: A promising approach to develop 21st century skills. I-managers' Journal on School Educational Technology, 9(22), 1-7.

Sendur, G., \& Toprak, M. (2013). The role of conceptual change texts to improve students' understanding of alkenes. Chemistry Education Research and Practice, 14(4), 431449. doi: 10.1039/C3RP00019B 
Şengören, S. K., Tanel, R., \& Kavcar, N. (2009). Students' difficulties about the wave pulses propagation on a rope. Journal of Turkish Science Education, 6(1), 50-59.

Shunk, D. H. (2009). Learning Theories from an Educational Perspective, Ankara: Nobel Publication.

Sinanoğlu, K. (2017). The effects on 6 th class student's cognitive load, academic success and permanency of concept cartoons and conceptual change texts. (Unpublished master's thesis). Ordu University. Ordu.

Stephenson, P., \& Warwick, P. (2002). Using concept cartoons to support progression in students' understanding of light. Physics education, 37(2), 135-141.

Talan, T. (2021). The effect of simulation technique on academic achievement: A metaanalysis study. International Journal of Technology in Education and Science, 5(1), 17-36.

Taşlidere, E. (2013). The Effect of Concept Cartoon Worksheets on Students' Conceptual Understandings of Geometrical Optics. Education \& Science, 38(167), 144-161.

Taşlidere, E. (2015). A study investigating the effect of treatment developed by integrating the $5 \mathrm{E}$ and simulation on pre-service science teachers' achievement in photoelectric effect. Eurasia Journal of Mathematics, Science and Technology Education, 11(4), 777-792.

Taşlidere, E. (2016). High school students' misconceptions about mechanical waves: Are students aware of what they know and don't know. Ondokuz Mayis University Journal of Faculty of Education, 35(1), 63-86. doi: 10.7822/omuefd.35.1.7

Taslidere, E. (2020). Factors affecting 12th-grade students' physics achievement. Psychology in the Schools, 57(9), 1385-1403. doi: 10.1002/pits.22415

Tavşanc1l, E., \& Aslan, A. E. (2001). Content analysis and application examples for verbal, written and other materials. İstanbul: Epsilon Publishing.

Thomas, C. L., \& Kirby, L. A. (2020). Situational interest helps correct misconceptions: An investigation of conceptual change in university students. Instructional Science, 48(3), 223-241.

Tongchai, A. Sharma, M. Johnston, I. Arayathanitkul, K., \& Soankwan., C. (2009). Developing, evaluating and demonstrating the use of a conceptual survey in mechanical waves. International Journal of Science Education. 31(18), 2437-2457. doi:10.1080/09500690802389605

Treagust, D. F., \& Duit, R. (2008). Conceptual change: A discussion of theoretical, methodological and practical challenges for science education. Cultural Studies of Science Education, 3, 297-328. doi:/10.1007/s11422-008-9090-4

Tumanggor, A. M. R., Kuswanto, H., \& Ringo, E. S. (2020). Using four-tier diagnostic test instruments to detect physics teacher candidates' misconceptions: Case of mechanical wave concepts. Paper presented at the 5th International Seminar on Science Education 26 October 2019, Yogyakarta, Indonesia, retrieved from https://iopscience.iop.org/article/10.1088/1742-6596/1440/1/012059/pdf

van Garderen, D., Decker, M., Juergensen, R., \& Abdelnaby, H. (2020). Using the 5E instructional model in an online environment with pre-service special education teachers. Journal of Science Education for Students with Disabilities, 23(1), 1-13.

Wang, T.\& Andre, T. (1991) Conceptual change text versus traditional text and application questions versus no questions in learning about electricity. Contemporary Educational Psychology, 16, 103-116.

Widiyatmoko, A. (2018). The effectiveness of simulation in science learning on conceptual understanding: A literature review. Journal of International Development and Cooperation, 24(1), 35-43. 
Wilder, M., \& Shuttleworth, P. (2005). Cell inquiry: A 5E learning cycle lesson. Science Activities, 41(4), 37-43. doi: 10.3200/SATS.41.4.37-43

Wittmann, M. C. (2002). The object coordination class applied to wavepulses: analysing student reasoning in wave physics. International Journal of Science Education, 24(1), 97-118. doi:10.1080/09500690110066944

Yerdelen-Damar, S., \& Peşman, H. (2013). Relations of gender and socioeconomic status to physics through metacognition and self-efficacy. The Journal of Educational Research, 106(4), 280-289. doi: 10.1080/00220671.2012.692729

Yıldırım, A. \& Şimşek H. (2013). Qualitative research methods in the social sciences ( $^{\text {th }}$ edition). Ankara: Seckin Publishing.

Y1ldirım, B. (2017). The effect of conceptual change text enriched with concept cartoons on primary school candidates' conceptual understanding and attitudes towards simple electric circuits. (Unpublished master's thesis). Mehmet Akif Ersoy University, Burdur.

Zacharias, Z. C. (2005). The impact of interactive computer simulations on the nature and quality of post graduate science teachers' explanations in physics. International Journal of Science Education, 27(14), 1741-1767. doi:10.1080/09500690500239664 


\section{Appendix A}

\section{Misconception Identification Table}

No Identification Alternatives Properties of waves and graphical representation of wave motion

1 The wavelength of a wave is the distance between the successive crests of the wave in a displacement-time graph.

2 The displacement-time graph of a particle in a rope as a wave propagates through it $1.1 \mathrm{c}, 1.3 \mathrm{a}$ can only be represented by a sinusoidal graph.

3 No matter how the source of a wave moves, as long as the motion is periodic, the resulting motion of the particle in the medium will follow a sinusoidal path (4)

$7.1 \mathrm{a}$

7.1a, 7.3a Wave motion versus particle motion

$4 \quad$ The particles of a medium and the wave propagating through the medium move with 10.1(a) the same speed.

5 The particles of the medium follow the speed of the wave propagating through the medium, as the wave causes the particles to move.

6 The particles of a medium and the wave propagating through the medium have the same speed, as the wave causes the particles to move.

\begin{tabular}{lll}
\hline & Frequency of waves, source of waves and medium properties & $11.1(\mathrm{a})$ \\
\hline 7 & When waves propagate from a medium with lower mass density to a medium of & $11.3(\mathrm{a})$
\end{tabular}
greater mass density, their frequency decreases.

8 A medium with greater mass has greater inertia. Fewer waves can propagate through it 11.(a), 11.3(a) in a given time.

9 When waves propagate towards a medium with greater mass density, their frequency decreases. It is because greater mass density means greater inertia and fewer waves can propagate through the medium at a given time. Wave speed in medium with fixed properties

10 As the frequency of waves increases, wave speed increases.

$5.1(\mathrm{a})$

11 As the frequency of waves increases, speed increases because more energy is imparted to the particles of the medium.

12 As frequency increases, wave speed increases (using the formula $v=\lambda * f$ ).

13 With frequency constant, as amplitude increases, it takes a longer time for $5.1(\mathrm{~b}), 5.3(\mathrm{c})$ the waves to move up and down.

14 With frequency constant, as amplitude increases, the speed of wave decreases because it takes a longer time for the waves to move up and down.

15 If frequency is unchanged and amplitude increases, the energy and speed of the wave will not change.

16 Since amplitude does not appear in the formula $v=\lambda * f$, its increase does not have any effect on wave speed.

17 To make a pulse propagate through a string more quickly, it must be jerked more quickly and more strongly.

18 a. This is because the higher the frequency, the shorter is the period or wave motion.

19 b. This is to make the particles vibrate with larger amplitude and move with

6.1(a), 6.3(a)

6.1(c), 6.3(d)

6.1(c), 6.3(e)

8.1(a), 8.3(e) greater energy. 


\section{Appendix B}

\section{A Sample Concept Carton Worksheet}

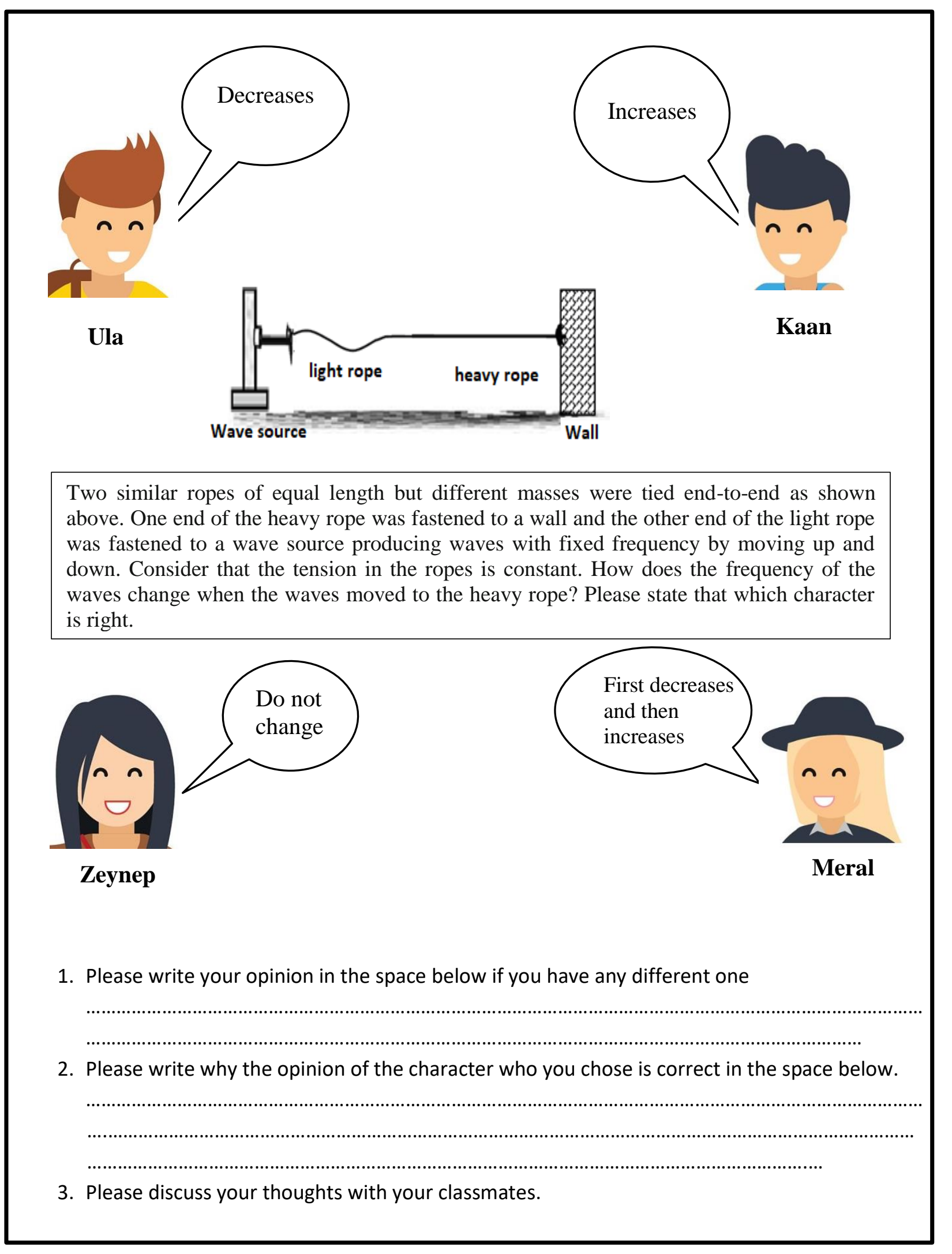




\section{Appendix C}

\section{A Sample Conceptual Change Text}

Light rope and heavy rope represent different mediums in the setup given in the concept cartoon worksheet. The question is how the frequency of the waves produced by a fixed frequency source will change when they pass from light rope to heavy rope. Studies show that most of the students have some common misconceptions on this subject.

If you count the time in seconds between the arrival of two consecutive waves, we measure the period (T) of the wave. In general, the period is the time required for two identical points (such as wave crests or wave through) of successive waves passing through a point. The same information is given in other quantity, which is the inverse of the period. This quantity is called frequency (f). In general, the frequency of a periodic wave is the number of wave crest (or troughs, or any point on the wave) that pass through a given point per unit of time.

Waves propagate at a special speed depending on the characteristics of the medium in which they are created. Frequency of a wave appears as wave property and always equal to the frequency of the source that created it. A high frequency wave source generates high frequency waves. Once the wave or pulse was produced, it travels with the same frequency regardless of the medium it travels. Although different mediums affect the speed of the pulses, they do not have an effect on their frequency.

Some students think that the frequency of the waves will decrease when they pass on heavy rope, as Ulaş states. The main reason of this idea generally results from students' tendency of relating the frequency of the wave to the characteristics of the medium. Learners believe that heavy rope resists the wave more and fewer waves will advance on the same time period on the heavy rope. But, in reality, the frequency of the pulse advancing in a medium does not change, it only depends on the source that created it rather than the properties of the mediums as stated above. The frequency of the wave source determines the frequency of the transmitted waves. Hence, once the pulse (or wave) is generated by the source, the frequency of it remains the same no matter where it goes. Some other students may agree with Kaan and Meral's opinions. Kaan thinks that the frequency increases during this transition. Meral says that the frequency decreases first when it passes to the heavy rope and then increases after a while. As explained above, since the frequency is not affected from medium, both Meral and Kaan have wrong opinions. In line with the information given above, we see that only Zeynep's opinion is correct among the other characters. No matter what medium the wave is created on, its frequency does not change whether it passes from light rope to heavy rope or vise verse. It travels with the frequency of the wave source creating it. Don't forget that the frequency does not depend on the medium, it only depends on the source that produced it. During this transition, only the speed and hence the wavelength of the waves decrease.

The same situation is also valid for the light rays and water waves. For example, approximately 600 million hydrogen atoms combine to produce helium nuclei at every second in the Sun. As a result of these fusion reactions, large amounts of heat and light energies are produced. The light rays illuminating our world come from the Sun. Consider the red light in the sun light. Its frequency does not change during its' travel from Sun to World's atmosphere, water medium or glass medium. Similarly imagine a pool with a different depth of water and water waves with a fixed frequency are generated by a source from the shallow side of the pool. When these waves pass into the deep region, their frequencies do not change, but their velocity and therefore their wavelengths decrease as the medium changes. Same situation occurs for the water waves moving from deep to shallow regions in the seas or oceans also. 


\section{Appendix D}

\section{A Sample Simulation Handbook Manual}

\section{Effect of Tension on Speed of Pulse}

You will discover the effect of the tension on the speed of the pulse on a rope whose thickness is the same everywhere (i.e., homogeneous).

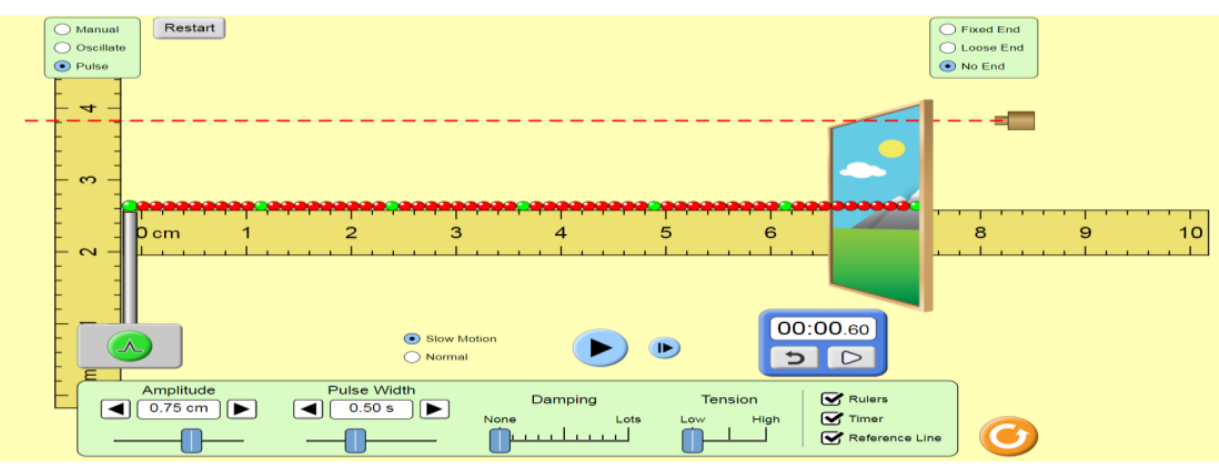

1. Fix the parameters on the simulation program (Amplitude: $0.75 \mathrm{~cm}$, pulse width: $0.5 \mathrm{~s}$, damping: None, Mode: pulse, slow motion) as shown in the figure above.

2. Prepare stopwatch ready for operation.

3. Run the simulation and the stopwatch by simultaneously pressing the green button given alongside $\Lambda$. Measure travelling time of the pulse on the rope from the first green bead to the last one, and note the value into the Trial 1 column in the table below.

\begin{tabular}{|l|c|c|c|c|}
\hline \multirow{2}{*}{ Tension } & \multicolumn{4}{|c|}{ Time, t(s) } \\
\cline { 2 - 5 } & Trial 1 & Trial 2 & Trial 3 & Average \\
\hline Low & & & & \\
\hline Medium & & & & \\
\hline High & & & & \\
\hline
\end{tabular}

4. Produce two more pulses as in the step above and write the travel times into the Trials 2 and Trial 3 columns. Then, calculate the average of the times obtained in Trial 1, Trial 2 and Trial 3 , and write it into "Average" column.

5. Then fill in the blanks in the table of interest by repeating the same process by setting the rope tensions as "Medium" and "High" levels.

Question 1.

How did the travelling times of the pulses change when the tensions on the rope was increased from low through the high levels?

Question 2.

How and why did the increase of the tension on the rope affect the speed of the pulses. Please write down your thoughts. 